\title{
Determination of alcohol- and sugar concentration in aqueous solutions using reflection terahertz time-domain spectroscopy
}

Møller, Uffe; Merbold, H; Folkenberg, J R; Jepsen, Peter Uhd

Published in:

Joint 32nd International Conference on Infrared and Millimeter Waves, 2007 and the 2007 15th International Conference on Terahertz Electronics. IRMMW-THz.

Publication date:

2007

Document Version

Publisher's PDF, also known as Version of record

Link back to DTU Orbit

Citation (APA):

Møller, U., Merbold, H., Folkenberg, J. R., \& Jepsen, P. U. (2007). Determination of alcohol- and sugar concentration in aqueous solutions using reflection terahertz time-domain spectroscopy. In Joint 32nd International Conference on Infrared and Millimeter Waves, 2007 and the 200715 th International Conference on Terahertz Electronics. IRMMW-THz. IEEE.

\section{General rights}

Copyright and moral rights for the publications made accessible in the public portal are retained by the authors and/or other copyright owners and it is a condition of accessing publications that users recognise and abide by the legal requirements associated with these rights.

- Users may download and print one copy of any publication from the public portal for the purpose of private study or research.

- You may not further distribute the material or use it for any profit-making activity or commercial gain

- You may freely distribute the URL identifying the publication in the public portal 


\title{
Determination of Alcohol- and Sugar Concentration in Aqueous Solutions using Reflection Terahertz Time-Domain Spectroscopy
}

\author{
U. Møller, H. Merbold, J. R. Folkenberg, and P. U. Jepsen
}

\begin{abstract}
We use self-referencing reflection $\mathrm{THz}$ spectroscopy to measure the alcohol- and sugar concentration with high precision in small volumes of aqueous solutions, independent of carbonation and the contents of yeast or other small organic particles.
\end{abstract}

Index Terms-Food industry, Liquids, Spectroscopy.

\section{INTRODUCTION}

$\mathrm{I}_{\text {the }}^{\mathrm{N}}$ $\mathrm{N}$ line with the rising demands on increasing food quality there is a need of new and fast measuring methods for rapid and objective determination of the state and quality of the food product on its way from the producer to the consumer. The development of new optical measuring methods for food control still implies fundamental studies of the interaction between light and matter. Therefore the development of such methods is not only an important issue for the food industry but also interesting from a general scientific point of view.

The traditional optical food analysis measurement methods are based on near infrared (NIR) and mid-infrared (mid-IR) spectroscopy. In these spectral regions the content of fat, proteins, carbohydrates, and amino acids in the product can be measured with great precision and different kinds of fat and carbohydrates can be detected. NIR and mid-IR have been perfected significantly during the past years and it is nowadays widely used in the industry, e.g. directly in process lines, for process control and in control laboratories.

The NIR and mid-IR spectral regions typically give intramolecular information such as the presence of different characteristic bonds, e.g. C-O, C-C, C-H and $\mathrm{C}-\mathrm{N}$, thus indicating the presence of certain molecules or groups of

Manuscript received April 4, 2007. This work was supported in part by the Photonics Academy Denmark.

$\mathrm{U}$. Møller is with the COM•DTU, Technical University of Denmark, DK2800 Kongens Lyngby, Denmark (e-mail: uffe@com.dtu.dk).

$\mathrm{H}$. Merbold is with the Institute of Mathematics and Physics, University of Freiburg, D-79104 Freiburg, Germany.

J. R. Folkenberg is with Foss Analytical A/S, Slangerupgade 69, DK-3400 Hilleroed, Denmark.

P. U. Jepsen is with the the COM•DTU, Technical University of Denmark, DK-2800 Kongens Lyngby, Denmark (e-mail: jepsen@com.dtu.dk). molecules in the sample. However, these spectral ranges give limited intermolecular information, e.g. about the alignment of molecules, the degree of hydrogen bonding to surrounding molecules and whether the molecules are a part of an amorphous or crystalline structure. Such information can often be found at longer wavelengths, in the terahertz region.

In spite of the lack of spectral features in the $\mathrm{THz}$ range of the dielectric function of amorphous materials and aqueous solutions, $\mathrm{THz}$ spectroscopy turns out to be very useful for identification of ingredients in solution, and also to determine their concentration with high accuracy. We will show how $\mathrm{THz}$ reflection spectroscopy can be used to determine the alcohol and sugar concentration with high accuracy, independent of the presence of microparticles, carbon dioxide, and other ingredients.

Sugar plays an important role in the food industry since it is used as a food preservative and is the most common sweetener. Therefore, the influence of sugar on the spectroscopic properties of the sample is important to know.

Alcohol concentration measurements are currently performed with specialized spectroscopic equipment, employing transmission measurements. The precise calculation of the alcohol content then relies on a chemometric analysis of the measured transmission spectrum in the vicinity of a characteristic vibrational band of the alcohol molecule in the near- or mid-infrared region. Therefore the precision of the measurement is highly sensitive to the thickness of the sample chamber as well as the preparation of the sample material.

We have developed a method for the determination of alcohol and sugar content in a wide range of alcoholic beverages that is insensitive to the content of for instance yeast and other organic residues as well as carbonation of the beverage. The method is based on a reflection measurement, and hence it eliminates the need for special sample preparation and it is well suited for integrated, continuous monitoring of the beverage during production. 


\section{EXPERIMENTAL TECHNIQUES AND DATA ANALYSIS METHODS}

For the measurements described here we use a method that we call self-referenced reflection $\mathrm{THz}$ time-domain spectroscopy. In the following we briefly describe the principles of this measurement method. Thrane et al. [1] and Rønne et al. [2,3] used similar methods for the determination of the temperature dependence of the dielectric function of pure water.

The fundamental geometry of a self-referenced reflection THz-TDS experiment is illustrated in Fig. 1. The input THz pulse is split up in two parts at the high-index silicon window. A measurement is carried out by a recording of the two pulses emerging from the reflection unit.

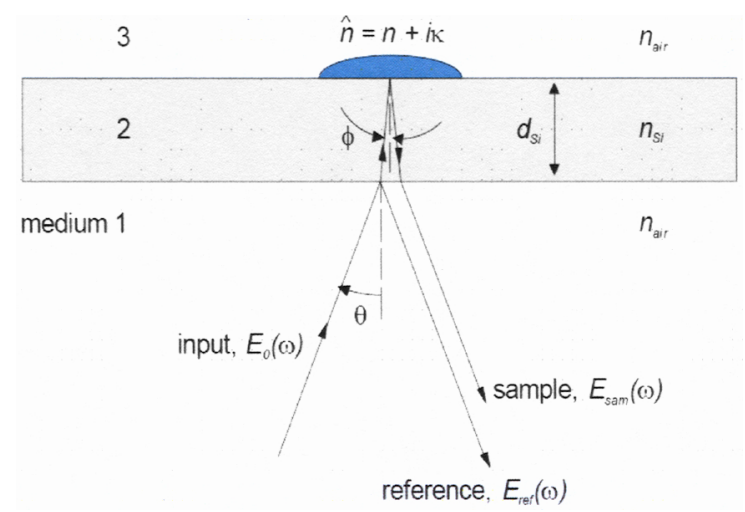

Fig. 1. The principle of self-referenced reflection THz-TDS.

A detailed analysis based on the propagation of an electromagnetic plane wave through the optical arrangement shown in Fig. 1 results in expressions that can be used for the determination of the dielectric function of the sample material placed on the upper side of the half-transparent silicon window. The complex index of refraction is determined by the recording and subsequent analysis of the time trace of the two reflected pulses emerging from the reflection head.

\section{RESULTS}

In Fig. 2 we show the absorption coefficient and the index of refraction of pure water, $30 \% \mathrm{w} / \mathrm{w}$ ethanol in water and $12 \% \mathrm{w} / \mathrm{w}$ sugar in water in the $0.1-1.1 \mathrm{THz}$ range. The spectral shapes of the absorption coefficient and index of refraction of these liquids have been characterized previously $[1,2,4]$. It has also been demonstrated that carbonation of the liquid and yeast or other small organic residuals in the liquid does not notably influence its dielectric properties [5].

When adding ethanol to water both the absorption coefficient and the index of refraction of the solution decrease substantially. Adding sugar to water does not have the same strong effect on the dielectric properties of the liquid. In fact, for low concentrations of sugar $(<20 \%)$ no distinct change of the index of refraction is observed whereas a small decrease of the absorption coefficient is seen.

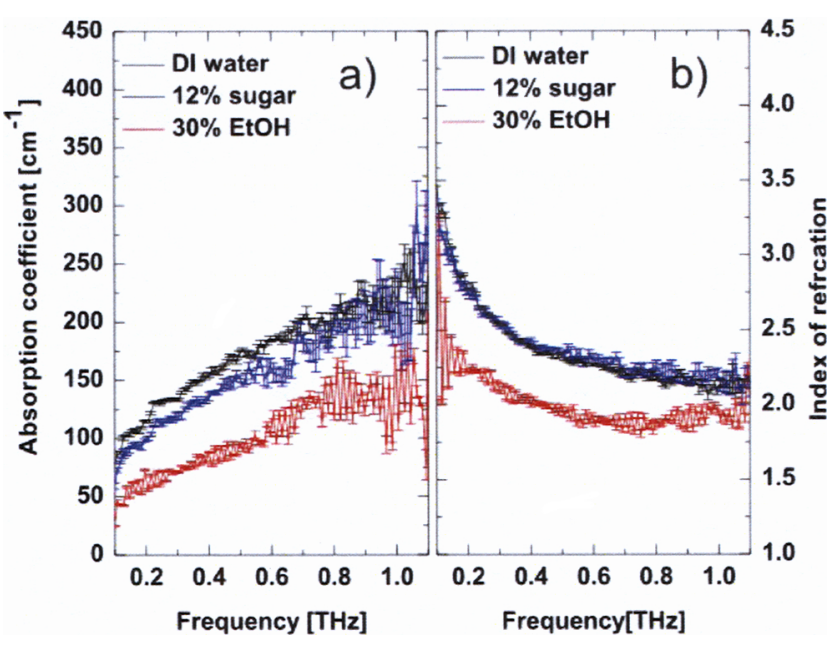

Fig. 2. a) absorption coefficient and b) index of refraction of distilled water, $30 \% \mathrm{w} / \mathrm{w}$ ethanol in water and $12 \% \mathrm{w} / \mathrm{w}$ sucrose in water in the $0.1-1.1 \mathrm{THz}$ range.

For a liquid where both ethanol and sugar are present this technique can therefore be used for simultaneous determination of both the ethanol concentration and the sugar concentration. The simultaneous determination of two components in the solution is possible since we measure both absorption and index of refraction over a side frequency range, and the presence of each of the components have different influence on these two quantities. The accuracy of the measurement is typically in the range of a few percent, currently mainly limited by the size of the reference data set and the temperature stability of the sample.

\section{CONCLUSION}

As might be expected, the size of the reference data set plays an important role in the accuracy of the determination of alcohol and sugar concentration in unknown samples. In the presentation we will highlight this point. Effects of the presence of more than one component in the aqueous solution will also be addressed.

\section{REFERENCES}

[1] L. Thrane, R. H. Jacobsen, P. Uhd Jepsen, and S. R. Keiding, "THz reflection spectroscopy of liquid water," Chem. Phys. Lett. 240, 330-333 (1995).

[2] C. Rønne, L. Thrane, P.-O. Åstrand, A. Wallquist, K. V. Mikkelsen, and S. R. Keiding, "Investigation of the temperature dependence of dielectric relaxation in liquid water by $\mathrm{THz}$ reflection spectroscopy and molecular dynamics simulation,” J. Chem. Phys. 107, 5319-5331 (1997).

[3] C. Rønne, Intermolecular liquid dynamics studied by THz-spectroscopy, Ph.D. Thesis, Aarhus University (2000).

[4] J. T. Kindt and C. A. Schmuttenmaer, "Far-infrared dielectric properties of polar liquids probed by femtosecond terahertz pulse spectroscopy," J. Phys. Chem. 100, 10373-10379 (1996).

[5] H. Merbold, U. Møller, and P. U. Jepsen, "Self-referenced reflection terahertz time-domain spectroscopy," (submitted 2007) 